\title{
CAMBIOS Y PERVIVENCIAS EN LAS MONTAÑAS DEL NOROESTE DE CASTILLA Y LEÓN: EL EJEMPLO DE LOS MONTES DE LEÓN, LA CABRERA Y SANABRIA ${ }^{1}$
}

\author{
María Jesús SÁNCHEZ MUÑOZ - Antonio MAYA FRADES - José María \\ SAN ROMÁN RODRÍGUEZ \\ Departamento de Geografía y Geología, Universidad de León
}

Recibido: 23/03/2010

Aceptado: 16/04/2010

RESUMEN: Este artículo se centra en el estudio de los cambios y de las pervivencias acaecidos durante las últimas décadas en las montañas del Noroeste de Castilla y León. Ha habido profundas transformaciones que quedan plasmadas en el conjunto de las estructuras y de los paisajes agrarios, en las nuevas fuentes de ingresos asociadas a los variados y ricos recursos naturales, en el crecimiento de la industria agroalimentaria o en la nueva valoración de los espacios culturales. A su vez, esa riqueza patrimonial, herencia de las sucesivas actuaciones humanas, se convierte en la base de la diversificación del origen de las rentas y del arraigo de los principios de la multifuncionalidad en los territorios rurales, tan necesarios para seguir avanzando en la propuesta de actuaciones encaminadas a afianzar el desarrollo rural sostenible.

PALABRAS CLAVE: Cambios, pervivencias, espacios de montaña, multifuncionalidad.

CHANGE AND SURVIVAL IN THE MOUNTAINS OF NORTH-WESTERN CASTILE AND LEON

ABSTRACT: This article focuses on an investigation of the features that have been transformed or have been retained during recent decades in the mountainous zones of the NorthWest of the Castile and Leon Region of Spain. There have been profound changes that have left their mark on the overall farming structures and landscapes, bringing with them new sources of income linked to the area's rich and varied natural resources, the growth of the food industry, and a new value set on the cultural heritage. In its turn, this rich inheritance, bequeathed by successive human actions over the ages, has become the basis for a diversification of the sources of income and for the firm implanting of the principles of multiple functionality in rural areas, which are highly necessary for continued advances in proposing actions aimed at underpinning sustainable rural development.

KEY WORDS Changes, survival, mountain areas, multifunctionality.

\footnotetext{
${ }^{1}$ Este trabajo se encuadra en el subproyecto centrado en el estudio de las montañas interiores y titulado Dinámica socioeconómica y articulación espacial de las montañas interiores en España. Experiencias y orientaciones para el desarrollo territorial sostenible y la política de cohesión territorial (Referencia SEJ2007-67655-C05-01).
} 
CHANGEMENTS ET SURVIES DANS LES MONTAGNES DU NORD-OUEST DE CASTILLE-ET-LEON

RÉSUMÉ: Le présent article se focalise sur l'étude des changements et des survies survenus au cours des dernières décennies dans les montagnes du Nord-ouest de la région de Castille-etLeón. De grandes transformations se sont produites, laissant leur empreinte dans l'ensemble des structures et des paysages agraires, dans les nouvelles sources de revenus provenant des ressources naturelles riches et variées, dans la croissance de l'industrie agroalimentaire ainsi que dans la nouvelle valorisation des espaces culturels. Cette richesse patrimoniale, héritage des interventions humaines successives, devient elle-même la base de la diversification des sources de revenus et de l'enracinement des principes de multifonctionalité dans les territoires ruraux, tellement nécessaires à l'avancement du programme d'interventions destiné à consolider le développement durable du milieu rural.

MOTS-CLÉS: Changements, survies, espaces montagneux, multifonctionalité.

\section{ALTERAÇÕES E SOBREVIVÊNCIA NAS MONTANHAS AO NOROESTE DE CASTELA E LEÃO}

RESUMO: Este artigo impresso enfoca o estudo das mudanças e do acontecido durante as últimas décadas nas Montanhas de Castela e Leão e que ainda permanecem. Houve transformações profundas, que estão plasmadas no conjunto das estruturas e da paisagem agrária, nas novas fontes de ingressos associadas aos mais variados e ricos recursos naturais, no crescimento da indústria dos alimentos ou na nova avaliação dos espaços culturais. Por sua vez, este rico património, herança das sucessivas atuações humanas, converte-se na base da diversificação das fontes da renda e do entrincheiramento dos princípios da multifuncionalidade das zonas rurais tão necessárias para o progresso na proposta de ações que visam o desenvolvimento rural sutentável.

PALAVRAS CHAVE: mudanças, sobrevivência, zonas de montanha, multifuncionalidade.

Las montañas del Noroeste de Castilla y León ocupan una posición periférica y alejada de las dinámicas socioeconómicas y de los ejes de desarrollo regional. A pesar de ello, disponen de variados y abundantes recursos que pueden servir de base para su propio desarrollo. Esas potencialidades se convierten en un hecho de gran trascendencia para lograr su diversificación productiva; se tienen que poner en marcha actuaciones encaminadas a impulsar la multifuncionalidad económica de estos territorios rurales con el fin de que sirvan para mejorar las fuentes de ingresos de la población local, poder fijar los efectivos demográficos, contribuir a frenar la despoblación o los índices de envejecimiento y mantener los paisajes y las herencias derivadas de las sucesivas actuaciones humanas a lo largo del tiempo.

El territorio que comprende este estudio se refiere a las comarcas leonesas de los Montes de León y La Cabrera y la zamorana de Sanabria. Se extienden por casi $3.800 \mathrm{Km}^{2}$ y están habitadas por 34.908 personas, siendo baja su densidad demográfica, $9,18 \mathrm{hab} . / \mathrm{Km}^{2}$. Dicha debilidad, junto a otros variados factores socioeconómicos o territoriales, puede servir para explicar los cambios y al mismo tiempo las pervivencias acaecidas en las mismas, asociadas a las profun- 
das transformaciones ocurridas en los espacios rurales y en general en el conjunto de la región o del propio país.

Esa dualidad de procesos, cambios y pervivencias, se aprecia claramente en este área espacial debido a que durante las últimas décadas ha experimentado muchas e intensas transformaciones que le han afectado muy directamente, manifestándose en diversas actuaciones. Entre las mismas se pueden mencionar los cambios en las estructuras y en los paisajes agrarios, las nuevas fuentes de ingresos vinculadas sobre todo con los recursos naturales, el afianzamiento de la industria agroalimentaria o la nueva valoración de los espacios culturales y naturales. De cualquier forma, no dejan de ser manifestaciones evidentes de lo acaecido en los espacios periféricos, siendo aún, si cabe, más acusadas e intensas si se localizan en áreas de montaña, como los de este estudio.

\section{LAS ESTRUCTURAS Y LOS PAISAJES AGRARIOS: LA FRAGILIDAD Y LA DEBILIDAD COMO EFECTOS MÁS INMEDIATOS.}

Las dinámicas en las estructuras agrarias de estas comarcas han mantenido, como en otros territorios de la Comunidad, una trayectoria regresiva motivada por diversas causas, entre las cuales sobresalen la propia evolución negativa de la población, la pérdida de peso específico del sector agrario, los cambios en los espacios rurales o en otras áreas espaciales y en el conjunto del sistema económico. Todo ello sirve para explicar la situación actual de estos territorios, cuyas manifestaciones más evidentes son el abandono, la pérdida de valor de algunos recursos naturales, el deterioro de los sistemas de producción agraria, sobre todo de los tradicionales, o el afianzamiento de nuevas formas de aprovechamiento de estos espacios periféricos y de montaña, en consonancia con los procesos de la multifuncionalidad productiva de los territorios rurales.

Si tomamos como referencia algunos indicadores, nos sirven sin duda, para conocer las dinámicas de los nuevos procesos socioeconómicos y de desarrollo endógeno de los espacios rurales. Dentro de los mismos se pueden mencionar la evolución demográfica y de los activos, de las explotaciones agrarias, de los titulares de las unidades de producción, de los usos del suelo, de los regímenes de tenencia o de la carga ganadera por citar algunos de los que tienen una clara manifestación no sólo de los cambios, sino de las pervivencias en los espacios rurales de las tres comarcas consideradas en este trabajo.

En general, se aprecia que la población ha mantenido un proceso de reducción continua motivada por la acusada emigración de décadas pasadas. En un análisis más pormenorizado de los indicadores demográficos comprobamos una regresión demográfica en los tres territorios montañosos, pero con algunas dife- 
rencias (CUADRO1). La comarca de Montes de León ha perdido más del 40\% de los efectivos de la década de los sesenta del siglo pasado ${ }^{2}$; dicha movilidad migratoria no ha cesado, ya que sigue dominando la emigración como se deduce de la correspondiente tasa negativa, $-2,7 \%$, salvo en Santa Colomba de Somoza, Santiago Millas y Brazuelo, donde los valores son de signo positivo. Los datos demográficos de Cabrera y Sanabria muestran un descenso continuado de la población desde 1960; en el período 1960-1981, alcanzó el -47,4\%, para la primera, y el $-40,5 \%$, para la segunda. Esta tendencia se mantiene en las décadas siguientes y en el intervalo de 2001-2008 la disminución en el conjunto de los municipios cabreireses alcanzó el -14,5\% y en los sanabreses el -7,7\%. Este proceso de pérdida de población está vinculado a unos índices migratorios negativos que han continuado durante la primera década del siglo XXI, en Cabrera el saldo migratorio medio anual es de $-17,3 \%$ y en Sanabria de $-4,3 \%$. Estos datos ilustran, por lo tanto, los efectos negativos de las migraciones y están condicionando la dinámica natural.

Asociado e influido por esa tendencia, se observa otro corolario de hechos. En los Montes de León la negativa dinámica natural se sitúa en torno al -14\% y en Magaz de Cepeda supera el -26\%; este elevado valor es consecuencia de la alta $\operatorname{mortalidad}^{3}(15 \%)$ y de la baja tasa de natalidad, $1 \%$; e incluso, en seis municipios no se puede calcular la tasa debido a la ausencia de nacimientos. Similares características se aprecian en las otras dos comarcas. En 2007, las tasas de natalidad son muy bajas en tres municipios de la Cabrera y en otros no ha habido nacimientos, como en Benuza, Castrillo de Cabrera y Castrocontrigo; lo mismo ha ocurrido en diez de Sanabria (Espadañedo, Hermisende, Justel, Lubián, Muelas de Los Caballeros, Pías, Porto, Requejo, San Justo y Trefacio); sólo en once municipios de ambas comarcas se han registrado nacimientos. Esos valores contrastan con las elevadas tasas de mortalidad debido a que estas zonas de montaña tienen una población muy envejecida; conviene poner de manifiesto, como algo llamativo, que, en 2007, sólo en el municipio de Requejo no hubo ningún fallecimiento.

Otro fenómeno que destaca es el acentuado envejecimiento de la población, tal como lo constata la tasa de vejez. En los Montes de León se halla en el $31,3 \%$, siendo en Magaz de Cepeda del $56 \%$ o en Luyego y en Valderrey del

\footnotetext{
${ }^{2}$ Dicha pérdida, en algunos municipios, equivale a más del 75\%, como en Villagatón, Brazuelo o Lucillo. Solamente Astorga ha ganado efectivos demográficos, un $20 \%$, debido a su situación de cabecera de comarca y que cumple determinadas funciones terciarias y tiene un relativo desarrollo industrial, localizado básicamente en el correspondiente polígono.

${ }^{3}$ En algunos municipios supera la tasa del 22\%, como en Lucillo, Luyego, Magaz de Cepeda y Villaobispo.
} 
$49,3 \%$, mientras que los jóvenes sólo representan el $10,2 \%$ de la población total y en Magaz de Cepeda, únicamente el 2,1\%. Esta situación se confirma aún más si nos fijamos en el índice de envejecimiento que es del 215 , es decir, por cada 100 jóvenes hay 215 personas con 65 y más años; en algunos municipios esa relación alcanza índices muy elevados, como en Magaz de Cepeda, 2.678, Luyego, 1.131, o Quintana del Castillo, 1.025. En las otras dos comarcas, en Sanabria y en La Cabrera la tasa de vejez equivale al $36,2 \%$ y al $35,1 \%$, respectivamente (CUADRO1). Pero si analizamos el índice de envejecimiento comprobamos que en seis municipios de La Cabrera y Sanabria alcanza valores muy elevados, como en Castrocontrigo, 1.184, en Asturianos, 1.084, en Hermisende, 1.418, en Pías, 1.183 o en Porto 2.600 (MAPA 1); se trata de índices que muestran un elevado nivel de envejecimiento, acentuándose mucho más debido a que muchos de ellos no cuentan con población joven. Por lo tanto, carecen activos para realizar cualquier actividad remunerada, la inmigración es la única posibilidad para que en un breve plazo de tiempo no se queden sin población, como de hecho ha ocurrido en el núcleo de población de Escuredo, en el municipio de Rosinos de la Requejada.

Cuadro 1. Indicadores demográficos.

\begin{tabular}{lrrrrrrrr}
\hline & $(1) \%$ (2) \%o & $(3)$ & $(4) \%$ & $(5) \%$ & $(6) \%$ & $(7) \%$ & $(8) \%$ \\
\hline Montes de León & $-13,99$ & $-2,71$ & 305,9 & 31,34 & 10,25 & 71,19 & 5,97 & 63,34 \\
La Cabrera & $-11,12$ & $-17,32$ & 418,6 & 35,09 & 8,38 & 76,92 & 2,24 & 76,52 \\
\hline Prov. de León & $-4,94$ & 3,71 & 214,6 & 24,40 & 11,37 & 55,69 & 6,47 & 60,38 \\
\hline Sanabria & $-11,60$ & $-4,35$ & 427,8 & 36,15 & 8,45 & 80,49 & 4,63 & 69,69 \\
\hline Prov. de Zamora & $-7,32$ & 4,13 & 263,8 & 28,15 & 10,67 & 63,64 & 8,18 & 55,4 \\
\hline
\end{tabular}

Notas: (1) Dinámica natural: 2007; (2) Movilidad migratoria: 2002-2007; media anual; (3) Índice de envejecimiento (viejos/jóvenes*100): 2008; (4)Tasa de vejez: 2008; (5) Tasa de juventud: 2008; (6) Tasa de dependencia: 2008; (7) Titulares agrarios < de 35 años (1999); (8) Titulares agrarios > a 55 años (1999).

FUENTE: Caja España, 2009; INE: Censo Agrario, 1999. (Elaboración propia)

Similares conclusiones se obtienen de la tasa de dependencia en los Montes de León, que se sitúa en el 71,2\%; se trata de una elevada tasa, que alcanza valores muy altos en Magaz de Cepeda (141,2), Valderrey $(128,5)$, Lucillo $(123,3)$ o en Luyego $(115,8)$, lo que demuestra el acusado grado de dependencia existente en esta comarca leonesa, pues dicha ratio mide la relación entre la población dependiente ( $<$ de $15 \mathrm{y}>$ de 64 años) y las personas en edad laboral (16-64 años); al mismo tiempo, de ello se deduce la debilidad de las estructura económicas, que no son capaces de crear los suficientes empleos para reducir la dependencia y mejorar la situación socioeconómica del área (CUADRO 1).

De todo ello se deduce un panorama demográfico bastante negativo; son municipios con graves problemas que requieren que se lleven a cabo políticas de- 
mográficas activas, pero acompañadas de adecuadas actuaciones económicas para lograr la fijación de la población joven, evitar la despoblación e incidir en la correspondiente renovación generacional. Dicha situación se agrava aún más en los Montes de León si nos fijamos en los titulares de las explotaciones agrarias, en los que, junto a su progresiva reducción, el acusado envejecimiento se ha convertido en una de sus notas más características. En efecto, casi las dos terceras partes de los titulares tienen 55 y más años, llegando en algunos casos, como en Lucillo o en Quintana del Castillo, a superar el umbral del $80 \%$, lo que denota el grado de envejecimiento de estos municipios, redundando negativamente en el conjunto del sistema económico. Algo similar ocurre en las comarcas de La Cabrera y Sanabria, donde dichos titulares de explotaciones presentan el 76\%, en la primera, y el 69\%, en la segunda (CUADRO 1); asimismo, a nivel municipal se comprueba que en cuatro municipios los dichos titulares rebasan el $80 \%$, como en los términos municipales de Encinedo el $86 \%$ y en el de Truchas el $85 \%$, en La Cabrera, y en el segundo los de Palacios de Sanabria, el $81 \%$ y el de Robleda- Cervantes, el 81\%, en Sanabria. Al mismo tiempo ese panorama, se acentúa aún más sin tenemos en cuenta el escaso peso de los titulares con menos de 35 años, que solamente representan en los Montes de León el 6\% del censo, siendo en Magaz de Cepeda y en Santiago Millas del 3\%, lo que pone de manifiesto la debilidad demográfica de estos espacios rurales (CUADRO 1); este hecho se convierte en un serio obstáculo a la hora de requerir gente joven que sea capaz de poner en marcha iniciativas relacionadas con el desarrollo endógeno y con los principios de la multifuncionalidad de los territorios rurales. No cabe duda de que la despoblación y sus efectos más inmediatos se convierten en severos problemas en estos territorios de montaña, al igual que otros territorios de la provincia, sobre todo si se quieren acometer actuaciones vinculadas con el aprovechamiento y la valoración de sus variados recursos culturales y naturales (MAYA, SÁNCHEZ MUÑOZ y SAN ROMÁN, 2009).

Estas dinámicas demográficas regresivas están influyendo en la propia evolución de las estructuras agrarias, sobre todo comportándose como los factores más evidentes que explican, en cierto modo, todo el proceso acaecido en estos territorios rurales. Una prueba evidente es la evolución de los activos agrarios, que han mantenido una tendencia decreciente, al mismo tiempo que se ha llevado a cabo la desaparición de los sistemas de producción tradicionales, ha continuado la pérdida demográfica por la emigración, se ha reducido el peso específico del sector agrario o se ha afianzado el proceso de sustitución del factor trabajo por el técnico. En fin, todo ello se ha manifestado en que en la actualidad sólo trabaje en el sector primario de la comarca de Montes de León el 9,3\% de los activos y en la de Sanabria el 12,7\%, siendo superiores a la media provincial (CUADRO2). No obstante, hay municipios que presentan unas características más agrarias, en los que las proporciones siguen siendo elevadas, por encima 
del 35\%, como en Lucillo, Luyego, Quintana del Castillo, Santa Colomba de Somoza, Valderrey, Villagatón o Villamejil, en los Montes de León; en Sanabria en cinco municipios, en concreto en Asturianos, 51\%, Espadañedo, 57\%, Justel, 78\%, Pías, 52\%, o en Rosinos de la Requejada, 39\%, y en La Cabrera Castrillo de Cabrera, con el $46 \%$.

Mapa 1. Índice de envejecimiento en las montañas del NW, 2008.

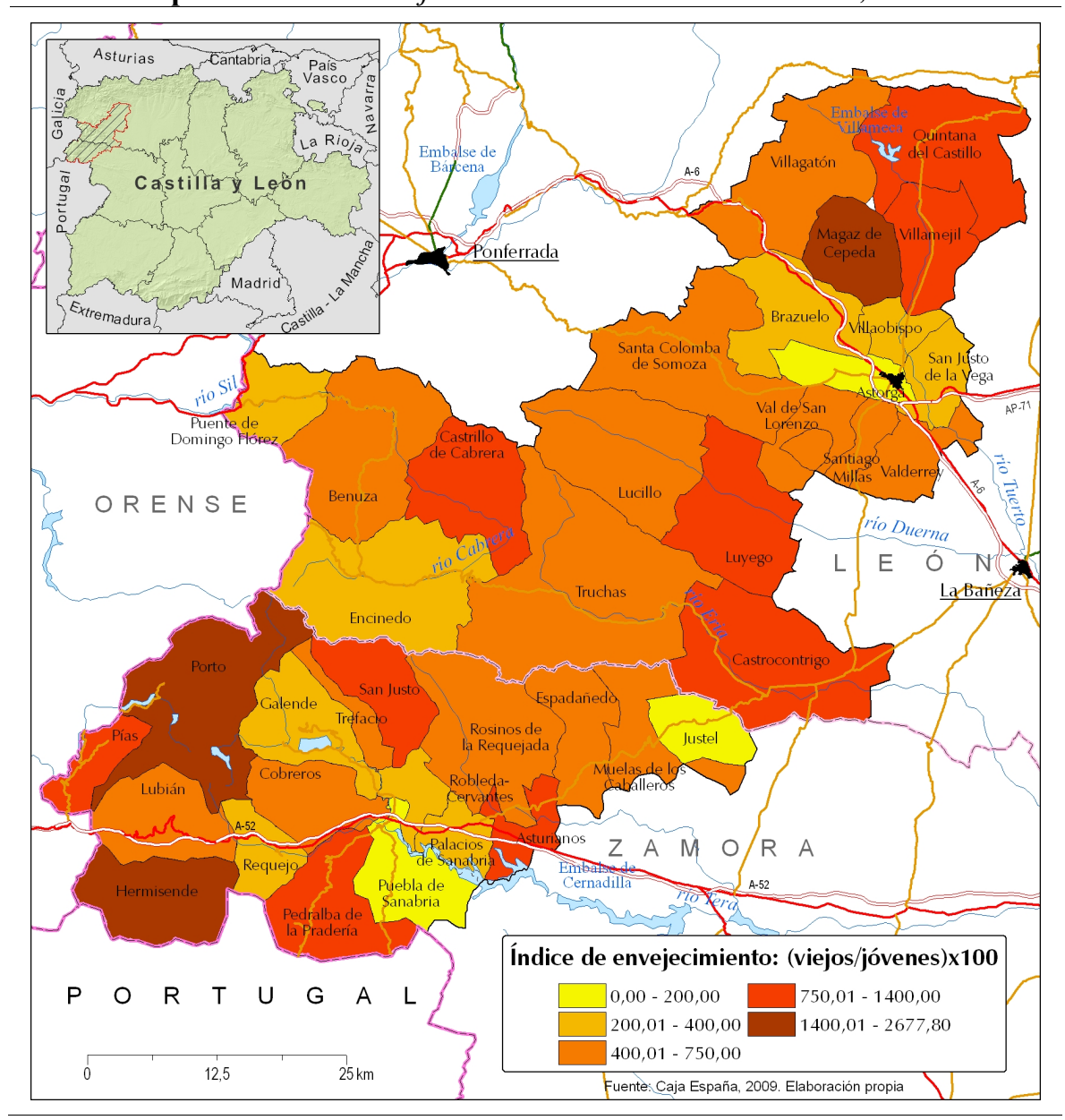

Esos cambios también se han puesto de manifiesto en las dinámicas de las propias estructuras agrarias. Dentro de las mismas, se observa que el censo de las explotaciones agrarias se ha reducido mucho debido a la confluencia de los factores anteriormente descritos; en la actualidad, ha desaparecido, en los Montes de León, el $45 \%$ de las unidades de producción que había en la década de los ochenta del siglo pasado, alcanzando cotas muy elevadas en algunos muni- 
cipios, como en Villagatón, el 90\%, o en Astorga, el 76\%; en las comarcas de Sanabria y de la Cabrera la reducción ha supuesto el $65 \%$ y el $58 \%$, respectivamente. Pero debemos poner de manifiesto que en algunos municipios estos porcentajes son más elevados, por encima del $90 \%$, como en Requejo $93 \%$ y en Trefacio 92\%. Pero si nos centramos en el intervalo del 70 al 90\%, son diez términos municipales los afectados: en La Cabrera, Castrillo de Cabrera y Truchas, y en Sanabria, Cobreros, Espadañedo, Galende, Hermisende, Lubián, Pedralba, Porto y San Justo. Es decir, están incluidos todos los municipios que integran el Parque Natural del Lago de Sanabria; así pues, el turismo y la existencia del espacio protegido no han favorecido la consolidación de unas explotaciones agrarias que encuentren acomodo dentro de las nuevas actividades productivas relacionadas con el turismo y el ocio y, por su puesto, no han sido capaces de que el sistema de producción tradicional se adapte a la situación actual. A su vez, se ha de tener en cuenta la situación de algunos municipios, como Rosinos de la Requejada, en el que el descenso no ha sido tan acentuado; los factores que lo explican se hallan, por un lado, en el mantenimiento de pequeñas explotaciones dedicadas a la plantación de castaños para venderlos luego a particulares o a las instituciones; $y$, por otro, la pervivencia de pequeñas explotaciones ganaderas de ovino o caprino, que están gestionadas mediante el sistema tradicional del cuidado de los rebaños sólo durante un determinado número de días al año en función de las cabezas de ganado (conocido en algunos lugares como vecera). Todo ello incide, en cierta medida, en que estén en actividad estas pequeñas explotaciones gestionadas por jubilados o por las familias de los trabajadores del sector secundario, principalmente construcción, sirviendo claramente como complemento a la economía familiar

Cuadro 2. Características de las estructuras agrarias.

\begin{tabular}{lrrrrrrrr}
\hline & $(1) \%$ & $(2) \%$ & $(3) \%$ & $(4) \%$ & $(5) \%$ & $(6) \%$ & $(7) \%$ & $(8)$ \\
\hline Montes de León & 9,31 & 74,54 & 7,04 & 29,98 & 18,57 & 1,91 & 82,70 & 0,15 \\
La Cabrera & 4,59 & 94,52 & 2,25 & 46,49 & 36,71 & 2,23 & 96,14 & 0,03 \\
\hline Provincia de León & 8,94 & 73,92 & 6,55 & 52,61 & 19,35 & 1,63 & 77,74 & 0,18 \\
\hline Sanabria & 12,70 & 81,73 & 8,53 & 30,95 & 39,11 & 3,90 & 90,88 & 0,08 \\
\hline Provincia de Zamora & 16,32 & 52,19 & 14,06 & 68,36 & 27,17 & 1,63 & 68,98 & 0,30 \\
\hline
\end{tabular}

Notas: (1) Activos agrarios: 2007; (2) Explotaciones agrarias < de 10 has: 1999; (3) Explotaciones agrarias > a 50 has: 1999; (4) Superficie Agraria útil (SAU): 1999; (5)

SAU/explotación: 1999; (6) Has./parcela: 1999; (7) Propiedad de la tierra: 1999; (8) Unidades Ganaderas (UG)/ha.; 1999.

FUENTE: Caja España, 2009; INE: Censo Agrario, 1999. (Elaboración propia

No deja de ser una prueba evidente de las consecuencias de la elevada emigración o de las modificaciones acaecidas en los espacios agrarios de los Montes de León. Dicha situación es similar a la propia evolución de las explotaciones agrarias con Superficie Agraria Útil (SAU) (MAPA 2); dentro de éstas, do- 
minan las de pequeñas dimensiones, en concreto las que tienen menos de 5 has. representan las dos terceras partes del censo total, equivaliendo a más del $85 \%$, en Lucillo o en Magaz de Cepeda; si le añadimos las de 5 a 10 has., la proporción asciende al $75 \%$, lo que pone de manifiesto el elevado peso de las unidades de producción de pequeño tamaño y la propia debilidad del tejido socioproductivo agrario. Dicha situación se afianza aún más con la consiguiente representación de las que tienen 50 y más has., que sólo suponen el 7\%. En el caso de las comarcas de Sanabria y La Cabrera, el peso de las explotaciones con menos de 5 has. supone el $71,6 \%$ y el $90 \%$ del censo total, respectivamente; nos hallamos ante explotaciones muy pequeñas, de autoconsumo, que alcanzan en los términos municipales de Robleda-Cervantes, el 92\%, Asturianos, el 90\% o en Galende y en Rosinos de la Requejada, el 86\%, influyendo, sin duda, en la desaparición del cultivo del centeno y de otras plantas forrajeras. De cualquier forma, esta desarticulada distribución de las explotaciones agrarias no deja de ser una prueba más de las reminiscencias de los anteriores modos de producción agrarios tradicionales, del escaso peso específico de los aprovechamientos agrarios o de los reducidos rendimientos, asociados a las propias condiciones ecológicas.

Esta débil estructura agraria también queda perfectamente plasmada en otros indicadores de gran trascendencia, como en la SAU media por explotación, que se halla en 18,6 has. en los Montes de León, similar a la media provincial, mientras que en la Cabrera es de 36,71 has. y en Sanabria, 39,1 has, que son superiores a los promedios provinciales (CUADRO 2). Los contrastes municipales son acusados, oscilando desde las 3,9 has., en Asturianos, la más reducida, a las 321,40 has, en Requejo. En los Montes de León, el nivel municipal oscila desde las 53 has., en Santa Colomba de Somoza, hasta las 6 has., en Magaz de Cepeda y en San Justo de la Vega (MAPA 2); son pequeños valores que demuestran en sí mismos las insuficiencias crónicas de las explotaciones. A pesar de ello, se observa que dichas medias han mejorado en comparación con las décadas precedentes debido a la disminución de la presión sobre la tierra o a la emigración, entre otras causas. Parecida tendencia se aprecia en el tamaño medio de las parcelas por explotación, aunque el promedio sigue siendo pequeño; en los Montes de León se sitúa en 1,9 has., en La Cabrera, 2,2 has. y en Sanabria, 3,9 has. (CUADRO 2); en algunos municipios valores muy pequeños, como en RobledaCervantes (0,4 has.), Asturianos (0,5), San Justo de la Vega (0,6 has.), en Val de San Lorenzo ( 0,9 has.), relacionado con sus mejores condiciones edáficas, mientras que en otros son más elevados, como en Brazuelo (8,2 has.) o en Villagatón $(5,2)$, debido a motivos opuestos. Similares características se deducen del número de parcelas por explotación, que asciende a 24, alcanzando en algunos municipios cifras muy elevadas, como en Lucillo o Villagatón, 74 parcelas, asociado a la ausencia de políticas de concentración parcelaria o a los escasos rendimientos agrarios de estos suelos, lo que redunda en detrimento de actua- 
ciones encaminadas a mejorar la rentabilidad de este área, como la mecanización u otras medidas tecnológicas. Estas características están, a su vez, confirmadas por la escasa proporción de $\mathrm{SAU}$, que en conjunto equivale solamente al $30 \%$ de la superficie total, teniendo en algunos municipios proporciones muy pequeñas, como en Brazuelo (10,7\%) o en Villagatón (4,5\%), mientras que en otros supera el $60 \%$, siendo ligeramente superior a la media provincial, como en San Junto de la Vega, Valderrey, Val de San Lorenzo o Villaobispo. Sin duda alguna, no dejan de ser claras manifestaciones y permanencias de los sistemas de producción y de los modelos de organización precedentes, que han evolucionado muy poco en estos municipios debido a sus propias características geográficas y socioproductivas y a las funciones que cumplen en el actual sistema económico.

Similar situación se aprecia en los aprovechamientos agrarios, en los que las tierras labradas han experimentado una continua regresión, mientras que los otros usos han mejorado su posición. En conjunto, en los Montes de León el terrazgo se ha reducido en más del 35\% de su superficie, salvo en Magaz de Cepeda, que ha habido un ligero incremento; en la comarca de La Cabrera se ha producido una elevada disminución, siendo Castrocontrigo el que menos superficie de labradío ha perdido, el 21\%; y en la comarca de Sanabria la reducción se halla en el 70\%, aunque hay dos municipios -Trefacio y Porto- en los que no se contabiliza ninguna superficie labrada, mientras que en Rosinos de la Requejada aumenta la superficie de labradío, en un 46,26\%, debido a que algunas explotaciones se ha inscrito con el fin de percibir ayudas de la Unión Europea. En los Montes de León, en la actualidad, sólo el $11 \%$ está dedicado a tierras de labor, suponiendo únicamente en Lucillo, el 0,3\%, o en Villagatón, el 1\%, lo que denota su escasa relevancia, mientras que en San Justo de la Vega dicha proporción es mayor, el 58\% de su término, relacionado con su localización en plena vega del río Tuerto, lo que le otorga una mayor vocación agrícola.

Los cultivos con mayor presencia en los Montes de León son los herbáceos, representando más del 98\% del terrazgo; cumplen funciones complementarias para la alimentación de la cabaña ganadera, que ha tenido a lo largo del tiempo una clara presencia y ha cumplido un importante papel económico en la comarca. También se deben tener en cuenta otros cultivos que gozan de una elevada demanda en el mercado por su calidad, aunque carecen de una marca o indicación geográfica que asegure que el producto llega al consumidor con las debidas garantías; dentro de los mismos se pueden mencionar los habones de Sanabria, siendo muy difícil alcanzar la consiguiente rentabilidad, ya que las explotaciones se hallan gestionadas por titulares de edad avanzada, que tienen como principal fuente de ingresos las pensiones de la Seguridad Social. Además, no podemos olvidar las dificultades existentes en estos municipios en los que no se 
ha realizado la concentración parcelaria y, por lo tanto, los procesos de mecanización agrícola resultan complicados por las condiciones ecológicas y por la parcelación de las explotaciones

Mapa 2. Explotaciones con SAU y su tamaño medio, 1999.

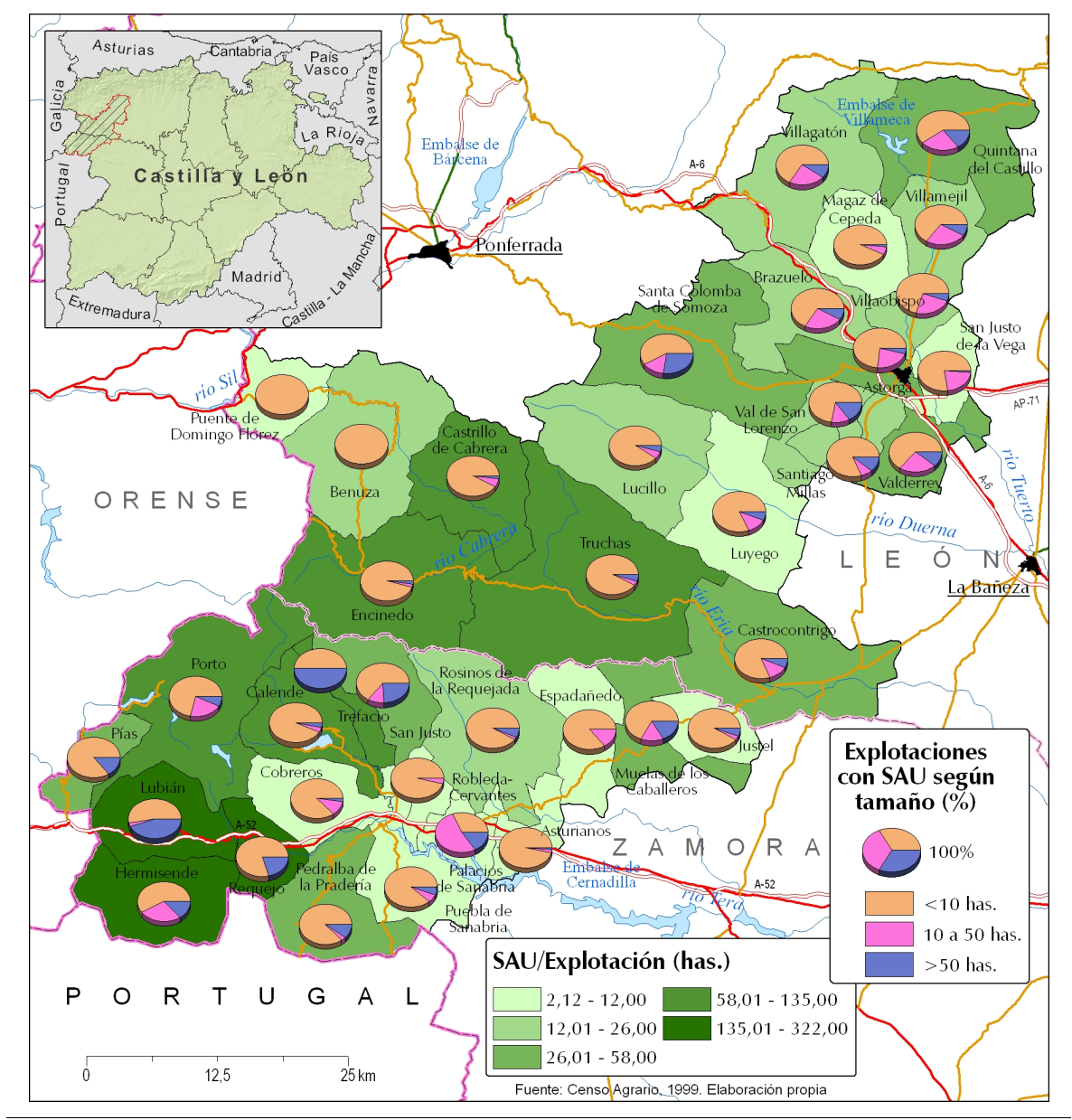

Los cultivos leñosos también aparecen en los Montes de León, en concreto el viñedo y en menor medida los frutales, aunque su presencia es reducida, destacando, en cierto modo, en San Justo de la Vega o en Villaobispo, debido a sus mayores posibilidades y a su mejores condiciones edáficas para su desarrollo. Asimismo, el viñedo aparece en La Cabrera, en particular en Puente de Domingo Flórez, que está incluido dentro de la D. O. Vinos del Bierzo, aunque en la mayoría de los municipios, como en Benuza, ha quedado reducido a parcelas diminutas. 
La escasa presencia del terrazgo contrasta con la destacada superficie de otros aprovechamientos silvo-pastoriles que han definido tradicionalmente a esta comarca. Los pastos y pastizales ocupan casi la quinta parte del espacio de los Montes de León, siendo ligeramente inferior a la media provincial, aunque en algunos municipios supera el umbral del 40\%, como en Quintana del Castillo, Valderrey o en Val de San Lorenzo, mientras que otros presentan menores aptitudes, hallándose por debajo del 4\%, como en Luyego, San Justo de la Vega o Villagatón. De cualquier forma, han constituido el soporte para el mantenimiento de una amplia cabaña ganadera, que aportaba ingresos económicos a las familias campesinas durante el dominio del modo de producción tradicional, contribuía a su economía de autoconsumo y se explotaba por medio de sistemas de producción semiextensivos. Esos mismos criterios se han mantenido a lo largo del tiempo y en la actualidad hay 16.648 Unidades Ganaderas (UG), que equivalen al 7\% de la cabaña provincial; los municipios con mayor cabaña son Astorga (3.546 UG), San Justo de la Vega (2.553 UG), Santa Colomba de Somoza (1.682 UG) y Val de San Lorenzo (1.684 UG). Parecidas características se derivan de la carga ganadera, que presenta un valor similar a la media provincial, en concreto $0,15 \mathrm{UG}$ /ha (CUADRO 2), correspondiendo los más elevados a Astorga (0,84 UG/ha.), San Justo de la Vega (0,60 UG/ha.) o Val de San Lorenzo (0,40 UG/ha.); se trata de una adecuada relación entre el territorio comarcal y el censo ganadero, que pone de manifiesto el pertinente aprovechamiento de estos abundantes recursos naturales.

En las comarcas de Sanabria y La Cabrera la carga ganadera se sitúa en 0,08 $\mathrm{UG} / \mathrm{ha}$. y en $0,03 \mathrm{UG} / \mathrm{ha}$., respectivamente; son densidades pequeñas que ponen de manifiesto el reducido censo ganadero y la amplia superficie de ambas comarcas. Asimismo, en Sanabria hay 8.721 UG, que equivalen al 3,4\% de la ganadería provincial, siendo el ganado bovino el predominante con $4.509 \mathrm{UG}$ que corresponde a la mitad de la cabaña; dentro de ella sobresale la presencia de una raza autóctona en peligro de extinción, la denominada Alistano-Sanabresa; dicha raza, que produce una excelente carne de calidad y su puesta en valor podría servir para diversificar las fuentes de ingresos, no ha generado un incremento del número de explotaciones y tampoco se ha convertido en un factor para atraer a más población a este sector productivo, pues los titulares de las explotaciones ganaderas son personas envejecidas (SAN ROMÁN, 1998 y 2008). En La Cabrera se contabilizan 2.970 UG, que representan el 1,2\% de las UG de la provincia, destacando la especie bovina que supone casi la mitad de la cabaña comarcal. La debilidad de la ganadería está relacionada con las condiciones ecológicas, que no son muy favorables, y con la intensidad de la actividad minera que concentra los empleos mejor remunerados en esta comarca. 
Las especies ganaderas dominantes son las que requieren el factor tierra para su desarrollo y aprovechan de modo extensivo esos recursos. En los Montes de León, destaca sobremanera el ganado ovino y caprino, que representa el $42 \%$ del censo, alcanzando en algunos municipios proporciones muy elevadas, como en Brazuelo o en Santiago Millas, más del $80 \%$ del censo municipal; los abundantes pastos son apropiados para el sustento de este tipo de ganado. Le sigue en orden de importancia la cabaña bovina, con el $25 \%$ del censo, representando en algunos municipios más del 55\% del censo, como en San Justo de la Vega y en Villaobispo. Por último, se encuentra la cabaña equina, que sólo supone el $1 \%$ del censo comarcal, aunque en Santa Colomba de Somoza y en Villagatón supera el 3\%; estos animales ya no cumplen y no se adscriben solamente a las funciones tradicionales, sino más bien se han adaptado a las necesidades actuales, en las que se comportan como animales de renta, con capacidad suficiente para aportar ingresos monetarios a sus dueños. Además de esas especies, conviene mencionar el porcino que no se halla vinculado al territorio, se explota en régimen intensivo y representa el 16\% del censo ganadero comarcal, aunque en algunos municipios presenta elevadas proporciones, como en Valderrey (53\% del censo municipal) o en Astorga (37\%); desempeña, como en el pasado, una doble función; por un lado, satisface las necesidades del autoconsumo, es decir, las típicas y características matanzas familiares; y, por otro, sobre todo, aporta rentas a las explotaciones ganaderas, logrando, de este modo, la diversificación de las fuentes de ingresos en estos espacios rurales.

En Sanabria, como ya se ha comentado, la especie dominante es la bovina, con la mitad del censo, seguida del ovino-caprino, con $2.398 \mathrm{UG}(27,5 \%$ de la cabaña). En tres municipios, Galende (1.107 UG), Rosinos de la Requejada (1.107 UG) y Cobreros (844 UG), se concentra el 35\% de las UG de la comarca y en las explotaciones ganaderas de los dos primeros predomina la ganadería bovina, mientras que en el último, Cobreros, destaca el ovino-caprino. Nos encontramos ante explotaciones que tienen una gran importancia para el aprovechamiento de los pastos de altura en la Sierra de la Cabrera y en la de Segundera, cuyo aprovechamiento se ha realizado tradicionalmente; en la actualidad se presenta como la mejor opción para aumentar el tamaño de las explotaciones y hacerlas más rentables debido a que el ganado se puede alimentar con dichos pastos desde finales de la primavera y hasta comienzos del otoño. Son explotaciones, tanto las de vacuno como las de ovino, orientadas a la producción cárnica, permitiendo de este modo aprovechar de un modo más favorable los pastos. Asimismo, conviene reseñar que hasta finales de los años setenta algunas industrias lácteas no incluyeron estas zonas en los circuitos de recogida, por lo que hasta una época muy reciente no se intentó la especialización lechera; a su vez, con la entrada en la Unión Europea se abandonan definitivamente estos intentos de orientación láctea en la ganadería bovina de la comarca. Frente a esa situa- 
ción se encuentran otros tres municipios, Trefacio (66 UG), Pedralba de la Pradería (123 UG) y Espadañado (124 UG), que agrupan tan sólo el 3\% de la cabaña ganadera comarcal, mostrando así los desequilibrios en la distribución.

En la comarca de la Cabrera también la cabaña bovina, con 1.341 UG y el $45,2 \%$ del censo, es la especie más numerosa; le sigue en importancia el ovinocaprino, con 1.059 UG y el 35,6\% de la cabaña ganadera. Las mayores facilidades para el manejo de la ganadería bovina y las posibilidades que ofrece la explotación con los pastos de altura son los factores que han influido en este predominio. A pesar del abandono del sector agrario y de la edad avanzada de los titulares de las explotaciones, se ha producido un incremento del tamaño de las explotaciones respecto a fechas precedentes. Dentro de los municipios, Castrocontrigo, con 1.054 UG y el 35\% del censo comarcal, es el que concentra más cabaña ganadera, mientras que en el extremo opuesto se halla Puente de Domingo Flórez, con 68 UG y sólo el 1,6\%. Esta menor presencia se debe a las dificultades para disponer de prados por las ocupaciones mineras del monte y a la intensidad de la actividad extractiva en algunos términos municipales cabreireses.

Finalmente, en los Montes de León el espacio ocupado por las especies forestales equivale a la quinta parte de la superficie de la comarca, siendo ligeramente superior a la media provincial; denota su destacada presencia a lo largo del tiempo, cuyas manifestaciones más evidentes quedan plasmadas en el indudable papel desarrollado durante la vigencia de los modos de producción agrarios tradicionales, en los que abasteció de leñas y de madera para la construcción y la confección de aperos de labor con el fin de cubrir las necesidades de las familias campesinas. Incluso, en algunos municipios de Sanabria, permitió la comercialización de madera para la construcción del ferrocarril Zamora-Orense, inaugurado después de la guerra Civil, en la primera etapa del Franquismo. El municipio con mayor representación es Lucillo, con casi las tres cuartas partes de su término, al que le siguen Brazuelo (36\%) y Astorga (28\%). Son importante porcentajes, que ponen de relieve la relevancia de la cubierta vegetal de la comarca. En la actualidad, cumplen funciones ecológicas y económicas. En el primer caso, conviene mencionar la existencia de variados y ricos paisajes naturales que pueden servir de base para atraer visitantes y aportar ingresos a la población rural de la comarca; este patrimonio natural se debe preservar y utilizar con sumo cuidado con el fin de que contribuya al afianzamiento de los principios de la multifuncionalidad de los territorios rurales, tan necesaria en el momento presente si queremos mantener los espacios Ruales articulados y vivos. El segundo alude a la obtención de rentas agrarias por la venta de madera destinada a otros usos económicos; ya no cumple las funciones tradicionales de an- 
taño, sino que se ha adaptado a las necesidades actuales y a las nuevas demandas, en consonancia con los dominantes modos de producción.

Dentro del espacio de los Montes de León, destaca, sin duda alguna, el régimen de propiedad como sistema de tenencia dominante, tal como lo confirma que el $82,7 \%$ de la tierra se adscriba al mismo, siendo muy parecido al promedio provincial (CUADRO 2). A nivel municipal sobresalen los que superan el umbral del 92\%, como Villagatón, Brazuelo, Lucillo o Luyego, que contrastan con los menores valores de San Justo de la Vega (51,7\%) o Villaobispo $(44,7 \%)$. El predominio del sistema de propiedad resulta de gran interés para el buen desarrollo de las distintas fases del proceso de producción agrario, ya que permite que los titulares de las explotaciones acometan las correspondientes inversiones productivas para mejorar el funcionamiento de las unidades de producción y sirvan para incrementar la rentabilidad de las mismas. Le sigue en importancia el arrendamiento, con el 15\%, alcanzado las proporciones más elevadas en los dos últimos municipios, San Justo de la Vega (43\%) y Villaobispo $(51 \%)$.

Al margen de esos resultados que ponen de manifiesto la desigual situación de la tenencia de la tierra en los municipios, conviene mencionar otro aspecto que no aparece recogido en su sentido estricto en los censos, pero que ha cumplido fundamentales funciones en la economía agraria tradicional. Nos referimos a los bienes colectivos que han sido de vital importancia para el mantenimiento de la sociedad rural, sobre todo en los momentos del dominio de la economía de autoconsumo, pues aportaba determinados productos necesarios y esenciales para su supervivencia y que no podían acceder a los mismos si no hubiese existido y pervivido a lo largo del tiempo la propiedad comunal de la tierra. Representa, según las Células de la Propiedad del Catastro de Rústica, la mitad de la superficie de la comarca, alcanzando en algunos municipios elevadas proporciones, como en Lucillo, Luyego y Villagatón con más del 75\% (MAYA, PASCUAL y GÓMEZ SAL, 1991). La titularidad y la gestión de las tierras colectivas corresponden a diferentes entidades y administraciones públicas, que ponen de manifiesto, en cierto modo, su evolución histórica, su peculiar naturaleza y sus diversas actividades y políticas desarrolladas. Apenas han experimentado modificaciones desde las reformas desamortizadoras de mediados del siglo XIX y han permanecido casi inalterables hasta nuestros días; a veces, les han afectado algunas medidas administrativas o actuaciones de los vecinos, que han incidido sensiblemente en su situación originaria (MAYA, 1999).

Dentro de los bienes colectivos destacan los Montes de Utilidad Pública (MUP), que ocupan casi las dos terceras partes del espacio comunal, siendo los tres municipios anteriores los más representativos, además de Santa Colomba de Somoza (con más del $80 \%$ de la propiedad comunal municipal). La propie- 
dad de los mismos corresponde a los pueblos, aunque la gestión y el dominio útil recaen en el Servicio Territorial de Medio Ambiente de la Junta de Castilla y León. Dicho organismo se encarga de desarrollar las diversas actuaciones y políticas aplicadas sobre los mismos; en dichas actuaciones se incluyen el diseño y puesta en práctica de la política de repoblación forestal y otras labores selvícolas, el control de los incendios forestales, el talado y la venta de madera o la subasta y el arriendo de los cotos de caza, por citar algunas de ellas (MAYA, PASCUAL y CABERO, 1998). A su vez, esa cesión obligatoria de la titularidad y de la gestión de esos bienes por parte de las Entidades Locales o Municipales está generando tensiones entre las distintas administraciones $\mathrm{y}$, a veces, está teniendo consecuencias desastrosas en la propia conservación conjunto de los montes provinciales.

Todos los municipios de las comarcas de La Cabrera y de Sanabria están incluidos en la zona del Plan 42 de la Junta de Castilla y León para la prevención de incendios forestales. Los continuos incendios expresan las tensiones que en muchos casos se producen por la gestión de estas zonas forestales. La importancia para suministrar pastos y leñas de las zonas forestales ha ido desapareciendo progresivamente con la menor presión humana sobre el territorio y el cambio en los sistemas de aprovechamiento ganadero y forestal. También han influido en este proceso, en algunos casos, los conflictos sociales entre juntas vecinales y municipios, además de la explotación de los pastos o de los recursos cinegéticos y las políticas públicas, declarando un espacio protegido o incluido dentro de la Red Natura 2000 (SAN ROMÁN, 2000).

También las tierras comunales constituyen una parte importante de los bienes colectivos, equivaliendo al $36 \%$ de los mismos en la comarca. En todos los municipios se hallan presentes y anteriormente formaban parte del terrazgo, pero sus peores condiciones edáficas han incidido en su progresivo abandono y ahora casi siempre se destinan a pastizales o a usos forestales, dentro de los cuales sobresalen los matorrales. Sus propietarios son Las Juntas Vecinales que a lo largo del tiempo han velado por su conservación, han evitado su privatización y han regulado sus usos, que, en la mayoría de las ocasiones, estaban recogidos en las diferentes Ordenanzas Concejiles. El dominio útil corresponde a todos los vecinos que, bien de forma individual o colectiva, se han beneficiado de ellos. Han cumplido un importante papel histórico, ya que han servido de complemento para las economías campesinas, sobre todo durante la etapa agraria tradicional. Ahora, dichos bienes están casi infrautilizados debido a la disminución de la presión social, al elevado éxodo rural, a la despoblación y al progresivo envejecimiento y, además, han dejado de cumplir las funciones que tenían asignadas anteriormente y que eran fundamentales para el conjunto de la sociedad rural. 


\section{LA INDUSTRIA Y LA CONSTRUCCIÓN: SECTORES CON CLARAS PERSPECTIVAS DE FUTURO.}

En la comarca de Sanabria las empresas de construcción son las más numerosas (70,93\%) (CUADRO 3); su impulso está relacionado con la expansión de las segundas residencias de emigrantes que han abandonado la comarca hace algunas décadas y deciden regresar durante los períodos de vacaciones, para lo cual construyen o rehabilitan la vivienda familiar. A su vez, esta rama es la que más empleo genera, el 80,15\% del empleo comarcal; se trata de la única actividad que ha atraído a población joven, pues ésta no se ha incorporado al sector primario y, en algunas ocasiones, aparece dentro de la categoría de agricultores a tiempo parcial.

Las empresas de electricidad están relacionadas con la importancia de los parques eólicos instalados en los municipios de la Alta Sanabria, en concreto en Hermisende, Lubián y Pías. Dicha instalación ha generado algunos empleos que se concentran en el municipio de Lubián, pues la automatización de las centrales hidroeléctricas ha supuesto que los pocos puestos de trabajo que se localizaban en las inmediaciones de la central hayan desparecido.

Cuadro 3. Número de empresas.

\begin{tabular}{lrrrrr}
\hline & $A$ & $B$ & $C$ & $D$ & $E$ \\
\hline Montes de León & 125 & 4 & 0 & 97 & 226 \\
$\%$ & 55,31 & 1,77 & 0 & 42,92 & \\
La Cabrera & 23 & 3 & 24 & 37 & 87 \\
$\%$ & 26,43 & 3,45 & 27,59 & 42,53 & \\
Sanabria & 61 & 4 & 3 & 18 & 86 \\
$\%$ & 70,93 & 4,65 & 3,49 & 20,93 & \\
\hline Prov. de León & 2.837 & 61 & 125 & 1.663 & 4.686 \\
$\%$ & 60,54 & 1,30 & 2,67 & 35,49 & \\
\hline Prov. de Zamora & 1.176 & 33 & 30 & 653 & 1.892 \\
$\%$ & 62,20 & 1,74 & 1,58 & 34,48 & \\
\hline
\end{tabular}

A, Construcción; B, Energía; C, Industrias extractivas; D, Industrias manufactureras; E, Total

FUENTE: www.cajaespana.es 2009. (Elaboración propia).

En cuanto a la actividad extractiva, la proporción de empleos es muy pequeña, el 3,4\% del total de la comarca; dicha actividad está representada por la instalación de una empresa de extracción de áridos en Puebla de Sanabria y otras dos en Pías dedicadas a la explotación de rocas ornamentales. 
Las restantes empresas manufactureras corresponden a las diferentes industrias agroalimentarias. El peso específico de las mismas es pequeño, pues en la mayoría de las ocasiones las producciones se destinan al mercado local.

En la comarca de La Cabrera la situación es bien distinta. El principal sector económico es el minero, que se dedica a la producción de pizarra para vender, en un elevado porcentaje, al mercado internacional. Dicho sector es el que más empleos genera en actividades extractivas, construcción y manufacturas, que está claramente relacionadas con el aprovechamiento de la pizarra.

En los Montes de León la industria y la construcción emplean al 30,07\% de los activos, porcentaje ligeramente superior al provincial (28,34\%). Un porcentaje que muestra un fuerte desequilibrio tanto en su localización como en su composición sectorial, concentrándose en Astorga, el 64,6\% de las empresas y el $65,11 \%$ de los trabajadores, que es el municipio más dinámico por su tradición económica y por actuar como cabecera (MAPA 3). En cambio, en el resto de los municipios se aprecia una escasa representación (80 empresas), orientadas fundamentalmente a la rama alimentaria complementada por la industria de la madera. Además de la polarización o concentración de la industria otro rasgo que identifica al resto de municipios rurales de la comarca es su escasa industrialización, teniendo entre 1 y 23 empresas, salvo Villamejil que no dispone de ninguna.

\section{II.1. La Cabrera: la aplicación de métodos de producción intensivos en la extracción de la pizarra.}

La intensidad de la explotación minera en la comarca de la Cabrera está relacionada con la demanda del mercado internacional en los años setenta del siglo pasado, que va a influir en la exportación de pizarra y comienza una etapa de intensos cambios socioterritoriales. Dentro de los mismos, conviene mencionar, por un lado, la conversión de los agricultores en mineros, que obtienen remuneraciones mucho más elevadas en este sector productivo y, por otro, se ralentiza el proceso de cambios en el sector agrario. Las explotaciones agrarias de autoconsumo disminuyen y la principal fuente de empleos y riqueza pasa a ser la pizarra. Se inicia una etapa diferente para el sector primario; muchas explotaciones serán gestionadas por agricultores a tiempo parcial, en los que la prioridad consiste en mantener las producciones que permitan compatibilizar el empleo en la minería con el trabajo y las tareas en la explotación agraria. Por todo ello, las producciones de viñedo, las castañas y los cultivos de hortalizas y patatas adquieren una gran importancia junto a las pequeñas explotaciones de ganado ovino-caprino, que se complementan con el porcino, cuyo destino básico es el consumo familiar. Al mismo tiempo, en algunos casos el avance de la explotación minera a costa de las superficies forestales o agrícolas va a dificultar o im- 
pulsar el abandono de la explotación agrícola debido a la ocupación por parte de las instalaciones mineras de zonas de monte y pastos (SAN ROMÁN, 2003).

En esta rama minera, los empleos en La Cabrera representan un elevado porcentaje del total de los de la provincia de León, ya que trabajan en la comarca aproximadamente 1.000 operarios. Se han recogido los datos a escala provincial, dado que la Estadística Minera de España no hace una desagregación a nivel municipal. Al mismo tiempo, hemos observado en otros trabajos, que hemos realizado sobre este sector y comparado dichos datos con la Seguridad Social, que la cifra de empleos puede ser superior debido a su proximidad a los centros de producción orensanos; esa situación va a influir en que haya desplazamientos de población desde La Cabrera hasta las instalaciones productivas gallegas.

Mapa 3. Trabajadores en el sector industrial y en la construcción.

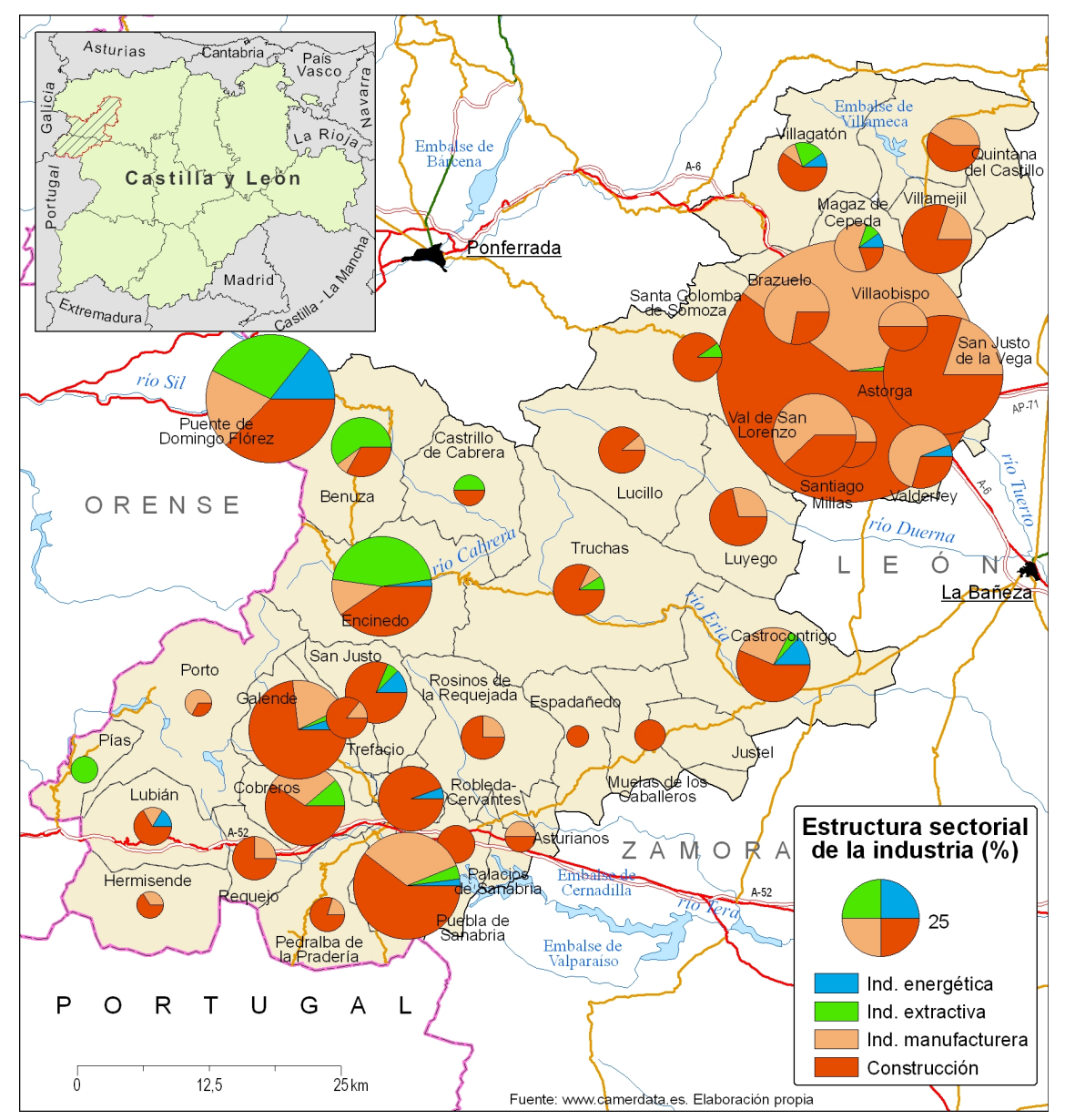


El crecimiento del sector ha sido muy rápido en León, ya que ha pasado de 324 empleos, en 1980, a 1.227 empleos, en el año 2000 (CUADRO 4). Asociado a esa situación, en esta comarca, que ha sufrido tradicionalmente un intenso proceso emigratorio, no existe mano de obra suficiente, por lo que es necesario que se desplacen diariamente a las instalaciones productivas desde las cabeceras comarcales vecinas de La Bañeza, Astorga o desde la ciudad de Ponferrada, e incluso desde la cabecera comarcal del Barco de Valdeorras, en Galicia. También se tiene que tener en cuenta que, en muchos casos, los empleados del sector minero más jóvenes optan por cambiar su residencia de la Cabrera hacia núcleos urbanos, que ofrecen más servicios y posibilidades de empleo a otros miembros de la familia: por todo ello, cuando se van de la comarca, se produce también el abandono de la explotación agraria familiar.

Cuadro 4. Evolución del número de canteras y empleos.

\begin{tabular}{rrrrrrr}
\hline \multicolumn{3}{c}{ Canteras } & \multicolumn{3}{c}{ Empleos } \\
\hline Años & León & España & LE/ES\% & León & España & LE/ES\% \\
\hline 1980 & 15 & 116 & 12,93 & 324 & 2292 & 14,14 \\
1996 & 30 & 137 & 21,90 & 889 & 3709 & 23,97 \\
2000 & 37 & 126 & 29,37 & 1264 & 4459 & 28,35 \\
2004 & 33 & 144 & 22,92 & 1038 & 4406 & 23,56 \\
2005 & 30 & 152 & 19,74 & 1227 & 4541 & 27,02 \\
\hline
\end{tabular}

FUENTE: Estadística Minera de España.

Asimismo, en el gráfico adjunto y en el cuadro 5 de exportaciones de pizarra aparece recogida la importante producción del sector en la comarca. Dicha relevancia queda constatada por los elevados ingresos económicos que aporta, si las comparamos con las del sector agrario. A su vez, en esta comarca se produce el $18 \%$ de las exportaciones españolas de pizarra y se generan más de mil empleos directos. Todo ello pone de manifiesto el contraste que existe con la debilidad del sector primario, que actualmente, excepto en Puente de Domingo Flórez, tampoco aparece como una opción de agricultura a tiempo parcial.

\section{II.2. Los Montes de León: cambios y pervivencias en la estructura del sec- tor industrial.}

Según el Instituto Lawrence R. Klein, en la actualidad, en la rama de industria y construcción existen 226 empresas sometidas al Impuesto de Actividades Económicas (IAE), que se corresponden con 521 licencias de actividades ${ }^{4}$. La

\footnotetext{
${ }^{4}$ Para el estudio de la actividad secundaria de la comarca se ha utilizado como fuente oficial el fichero de empresas de la Cámara de Comercio, actualizado en la página web de Camerdata, el anuario de Caja España, así como estudios previos realizados en el área de Montes de León, citados en la bibliografía.
} 
comarca de Montes de León posee una estructura dominada por la construcción, con 125 empresas $(55,31 \%)$ y 315 licencias $(60,4 \%)$, y la industria, con 101 empresas $(44,69 \%)$ y 206 licencias $(39,54 \%)$. A nivel general, las actividades industriales se apoyan en empresas de carácter familiar, que dan empleo a algunos miembros de la unidad familiar. El minifundismo empresarial queda constatado por el hecho de que el $87,5 \%$ son microempresas (1-5 trabajadores) y tan sólo el 0,7\% tiene más de 50 empleados (CUADRO 6). Entre los municipios encontramos de nuevo diferencias; por un lado, en la ciudad de Astorga están ubicadas empresas de todos los tamaños, desde las grandes, como la "Constructora Cepedana", la empresa "Noroeste Ganadero, SA", Dulces Mallorquina y Cecinas Pablo, hasta las empresas de carácter familiar. En cambio, en el resto de municipios dominan las unidades de carácter artesanal, poco habituadas a la cooperación interempresarial. Nos encontramos, pues, ante una realidad en la que la existencia de la pequeña empresa familiar sigue marcando la tónica dominante del panorama productivo e imprimiendo su sesgo particular a la organización y funcionamiento de un modelo de fabricación que se mantiene fiel a muchos de los aspectos que han marcado su personalidad a lo largo del tiempo. Otro rasgo común es la escasa o nula innovación tecnológica y la excesiva dependencia de Astorga y la capital provincial a través de las relaciones empresariales entre la red de proveedores, clientes y mercados.

Cuadro 5. Distribución de las exportaciones de pizarra en Castilla y León. Kg. (\%)

\begin{tabular}{|c|c|c|c|c|c|c|c|c|}
\hline & \multicolumn{2}{|c|}{1995} & \multicolumn{2}{|c|}{1996} & 1997 & \multicolumn{2}{|c|}{1998} & 1999 \\
\hline Castilla-León & \multicolumn{2}{|c|}{15,16} & 19,00 & & 17,83 & \multicolumn{2}{|c|}{19,39} & 19,39 \\
\hline León/España & \multicolumn{2}{|c|}{13,07} & 16,99 & & 15,93 & \multicolumn{2}{|c|}{17,60} & 17,46 \\
\hline \multirow[t]{2}{*}{ Leon/CyL } & \multicolumn{2}{|c|}{86,24} & 89,39 & & 89,34 & \multicolumn{2}{|c|}{90,77} & 90,04 \\
\hline & 2000 & 2001 & 2002 & 2003 & 2004 & 2005 & 2006 & 2007 \\
\hline Castilla-León & 19,26 & 21,60 & 20,94 & 21,38 & 22,35 & 21,94 & 22,24 & 22,73 \\
\hline León/España & 17,09 & 19,41 & 18,90 & 18,66 & 18,98 & 18,73 & 18,10 & 19,03 \\
\hline Leon/CyL & 88,75 & 89,87 & 90,25 & 87,28 & 84,90 & 85,35 & 81,40 & 83,72 \\
\hline
\end{tabular}

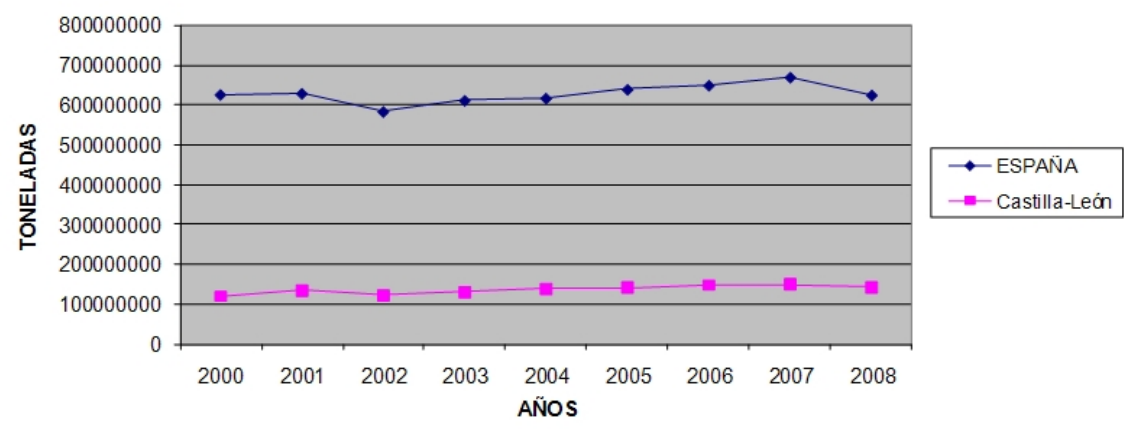

FUENTE: ICEX. 2009 
Por otro lado, la existencia de suelo industrial planificado supone uno de los cambios más significativos en los procesos de desarrollo y crecimiento económico, pues permite crear un marco idóneo para la instauración de naves industriales o comerciales, constituyendo una importante ventaja competitiva, a pesar de la rivalidad interterritorial existente. Sin embargo, tampoco se puede obviar la influencia que ejerce sobre los Montes de León la presencia de puntos localizados fuera del área de acción, en particular en León capital, en Villadangos del Páramo y en Ponferrada.

Cuadro 6. Distribución porcentual de los establecimientos según su tamaño en los Montes de León.

\begin{tabular}{|c|c|c|c|c|c|c|}
\hline \multirow{3}{*}{ Municipio } & \multicolumn{5}{|c|}{ Tramo de empleados } & \multirow{3}{*}{$F$} \\
\hline & \multirow{2}{*}{$\frac{\text { Pequeña }}{A}$} & \multicolumn{2}{|c|}{ Mediana } & \multicolumn{2}{|c|}{ Grande } & \\
\hline & & $B$ & $C$ & $D$ & $E$ & \\
\hline Astorga & 86,77 & 7,00 & 3,50 & 1,95 & 0,78 & 56,48 \\
\hline Brazuelo & 78,57 & 14,29 & 0,00 & 7,14 & 0,00 & 3,08 \\
\hline Lucillo & 100,00 & 0,00 & 0,00 & 0,00 & 0,00 & 1,54 \\
\hline Luyego & 92,86 & 0,00 & 7,14 & 0,00 & 0,00 & 3,08 \\
\hline Magaz de Cepeda & 83,33 & 16,67 & 0,00 & 0,00 & 0,00 & 1,32 \\
\hline Quintana del C. & 90,91 & 9,09 & 0,00 & 0,00 & 0,00 & 2,42 \\
\hline S. Justo de la Vega & 87,27 & 9,09 & 0,00 & 1,82 & 1,82 & 12,09 \\
\hline Sta. Colomba de S. & 100,00 & 0,00 & 0,00 & 0,00 & 0,00 & 1,98 \\
\hline Santiago Millas & 72,73 & 27,27 & 0,00 & 0,00 & 0,00 & 2,42 \\
\hline Valderrey & 75,00 & 25,00 & 0,00 & 0,00 & 0,00 & 2,64 \\
\hline Val de San Lorenzo & 96,00 & 4,00 & 0,00 & 0,00 & 0,00 & 5,49 \\
\hline Villagatón & 66,67 & 33,33 & 0,00 & 0,00 & 0,00 & 1,32 \\
\hline Villamejil & 94,44 & 5,56 & 0,00 & 0,00 & 0,00 & 3,96 \\
\hline Villaob. de Otero & 100,00 & 0,00 & 0,00 & 0,00 & 0,00 & 2,20 \\
\hline Total & 87,47 & 8,13 & 2,20 & 1,54 & 0,66 & 100,00 \\
\hline
\end{tabular}

A, 1 a $5 ;$ B, 6 a $10 ;$ C, 11 a $25 ;$ D, 26 a 50; E, 51 a $100 ;$ F, \% respecto a la comarca FUENTE: www.camerdata.es, 2010. (Elaboración propia).

En la comarca la dotación industrial planificada muestra una significativa oferta de suelo industrial, pues existen varios polígonos: Astorga, Brañuelas (Villagatón) y Valderrey (CUADRO 7). La mayor parte del suelo proyectado o en desarrollo se encuentra en el eje León-Astorga-Ponferrada, que aúna a tres de los cinco núcleos de más de 10.000 habitantes con que cuenta la provincia. Este eje está estructurado en torno a las vías de alta capacidad A-6 y AP-71 y se ramifica gracias a otros viales, como la propia A-6, planteándose en el futuro la creación de otros grandes viales en la provincia leonesa, como son PonferradaLa Espina, Ponferrada-Ourense, León-Bragança y León-Valladolid, que redun- 
darán en una mejora de la competitividad del eje aprovechando su céntrica situación dentro del cuadrante NW.

Dentro del suelo planificado destaca el "Polígono industrial de Astorga" desarrollado en cuatro fases; se trata de un polígono de promoción mixta, Ayuntamiento y Cámara de Comercio de Astorga, siendo el gestor GESTURCAL. El polígono se puso en marcha en los años noventa aprovechando el nudo de comunicaciones de la ciudad (A-6, la N-VI y la autopista León-Astorga AP-71) junto con las ventajas fiscales y económicas que estimularon la inversión y la creación de las empresas durante el llamado quinquenio expansivo, además de las provenientes de los fondos europeos de apoyo a las áreas desfavorecidas. Hasta ahora cuenta con una ubicación de aproximadamente 60 empresas que dan trabajo a más de 150 personas. El polígono industrial tiene un grado de ocupación del 63,93\%, ofertando suelo industrial a precio asequible y la dotación de servicios que demandan las empresas; además, el "Polígono industrial de Astorga" es uno de los pocos de la provincia que cuenta con un vivero de empresas.

El municipio de Villagatón muestra una dinámica distinta, pues debido a su posición se han generado una serie de flujos entre el municipio y la comarca vecina del Bierzo, en especial con Bembibre. De hecho, Brañuelas era el punto de encuentro entre la producción minera y el Ferrocarril hacia Galicia, lo que generó el asentamiento de industrias extractivas, en La Silva y Montealegre, y la implantación de empresas distribuidoras de antracita, el desarrollo de actividades de transporte y logísticas y el crecimiento del barrio de la Estación en esta localidad. Sin embargo, tras la crisis del sector minero y su posterior reconversión, algunas localidades han perdido su función productiva a pesar de contar el municipio con un polígono industrial. Dicho polígono no ha supuesto un revulsivo para la zona, por lo que su ocupación es escasa (52\%). Entre los cambios más importantes destaca la reciente compra de parcelas de una empresa americana, Ecospanus S.L., de reciclado de neumáticos, que prevé producir "negro de carbón" y combustibles a partir de la técnica de pirólisis flash. Esta iniciativa, preseleccionada por el Ministerio de Industria para recibir ayudas, supondría la creación de un importante número de empleos directos, aunque no se halla exenta de polémica por la posible contaminación derivada del proceso.

En Valderrey se encuentra otra área industrial de reciente instalación (2004) promovido por el Ayuntamiento, aprovechando su posición en la A-6 y AP-71 y la existencia, en los alrededores, de otras empresas desde hace 60 años: fabricación de piensos, fabricación de pequeñas máquinas agrícolas y de jardinería, industrias de despiece de carne y aserraderos. En este caso, el polígono tiene un bajo grado de ocupación, en torno al $12 \%$, dado que apenas existen proyectos empresariales ni industriales de importancia, ya que sólo se han instalado cuatro empresas, cuyas actividades se centran en la Producción de Envases, Reposte- 
ría, Automatismos y Equipos Eléctricos y Electrónicos y pequeña transformación de pieles.

Cuadro 7. Características del suelo industrial planificado en los Montes de León.

\begin{tabular}{lccc}
\hline & $A$ & $B$ & $C$ \\
\hline Municipio & Astorga & Villagatón & Valderrey \\
Promotor & municipal/privado & municipal & municipal \\
Año & 199 & 1999 & $2004 / 2007$ \\
Propietario & GESTURCAL & Ayuntamiento & Ayto./Privado(f.II) \\
Acceso & N-VI & Brañ.-Villam. & A-6 y AP-71 \\
Sup. ocupada $\left(\mathrm{m}^{2}\right)$ & 543.725 & 35.665 & 153.928 \\
Ocupación\% & 63,93 & 52,93 & 12,08 \\
\hline
\end{tabular}

A, Polígono Industrial de Astorga (Fase I y II, III y IV); B, Polígono Industrial de Brañuelas; C, Polígono Industrial de Valderrey

FUENTE: www.sueloindustrial.net

En San Justo de la Vega está en proyecto otra zona industrial con el objetivo de aprovechar la cercanía de Astorga debido a la consideración de que la oferta de suelo industrial y de equipamientos son factores claves para el asentamiento de empresas.

En los Montes de León la disposición de suelo industrial constituye un elemento clave en el desarrollo industrial de la zona tratando de adaptarse a la demanda del mercado pero sin dejar de lado la tradición que pervive en la estructura industrial. De hecho, en la comarca la actividad que tiene un mayor peso es la manufacturera, representada por un conjunto de empresas e instalaciones en ramas tan diversas como la alimentación, la madera, la textil, la fabricación de productos metálicos y la edición y artes gráficas. Se trata de empresas cuya importancia deriva de su grado de implantación y de lo que representan como actividades tradicionales pues la mayoría se concentran en los sectores industriales clásicos que tuvieron presencia en el pasado o basan su producción en el aprovechamiento de recursos locales, dominando la industria alimentaria y la industria de madera, que acumulan el $68,4 \%$ de las licencias.

En lo que afecta al sector secundario, Astorga es el municipio que concentra mayor número de licencias, 291 (55,85\% sobre el total de la comarca), siendo la principal actividad la rama de la construcción, con el 60,13\% de las licencias municipales, seguida de la industria manufacturera, el 39,8\% de las licencias debido a la implantación de la industria agroalimentaria (chocolates y confitería tradicional), seguida de la rama de la madera y artes gráficas y edición. Tras Astorga, que ostenta una hegemonía clara, se encuentran otro grupo de municipios en el que el porcentaje municipal representa entre el 5-12\% del total comarcal. Aquí se incluyen San Justo de la Vega (con implantación de la industria chaci- 
nera y de la construcción), y Val de San Lorenzo (con presencia de empresas textiles de gran tradición) (MAPA 4).

Dentro de la construcción dominan las empresas de pequeña dimensión (3 empleados/establecimiento), con especial concentración en Astorga. Las causas que han propiciado el desarrollo de este sector están relacionadas con la construcción de viviendas en la ciudad, la remodelación de viviendas en los pueblos promovidas por sus habitantes y por los descendientes que viven fuera y, por último, por la construcción de urbanizaciones en áreas cercanas. Se trata de una actividad en expansión con presencia en todos los municipios pero especialmente arraigada en Astorga, es decir, allí donde se localiza el mayor núcleo de población y la economía manifiesta mayor dinamismo.

En cuanto a la industria agroalimentaria, los Montes de León se caracterizan por el contraste entre las zonas en las que hay una industrialización débil y la ciudad de Astorga, donde la industria muestra una mayor diversificación productiva. En muchos casos, se aprecia la convivencia de actividades de gran tradición y en alza, entre las que destaca la industria del chocolate, la chacinería y la confitería, con empresas que se limitan al abastecimiento de la ciudad de Astorga en bienes de consumo cotidiano (panificación, bollería), y con otras industrias que ofrecen ciertos síntomas de dinamismo como las dedicadas a la elaboración de bebidas gaseosas, y fabricación de conservas. Entre las actividades tradicionales destaca la industria del chocolate, la fabricación de mantecadas y la chacinería.

La industria del chocolate pervive en la ciudad desde el siglo XVIII y en la actualidad se sigue elaborando con la calidad derivada de la tradición; una calidad que ya estaba avalada desde el siglo XIX como demuestra la presencia de galardones concedidos al chocolate de Astorga y que se exponen en el Museo del Chocolate (Londres, 1802, Barcelona 1912, Milán 1921). Varias causas son las que contribuyen a explicar la implantación de esta industria en la ciudad; en primer lugar, destaca la actividad de los arrieros maragatos que suministraban las materias primas procedentes de los puertos gallegos y efectuaban la distribución del chocolate elaborado a otros puntos de España para su venta. En segundo lugar, otro factor decisivo está relacionado con el clima seco y frío necesario en el proceso de enfriamiento sobre suelo del chocolate hasta la aparición de las cámaras frigoríficas. Finalmente, otra causa que apuntan ciertos investigadores está relacionada con la demanda de este producto por parte de sacerdotes y monjes pertenecientes a la diócesis de Astorga, pues no en vano Astorga era parada en el Camino de Santiago.

Más allá de las causas hay que destacar la influencia de este tipo de industria al crear sinergias, "pues generó la creación de industrias subsidiarias que se en- 
cargaban de la fabricación de envolturas y envases y de las campañas publicitarias así como, a partir del siglo XIX, de la fabricación de las máquinas necesarias para la mecanización del proceso de elaboración del chocolate" (GONZÁLEZ PÉREZ, 1999: 317). Una industria que en la actualidad apuesta por la elaboración artesanal, pero también por la difusión y promoción del pasado y presente de esta actividad, aspecto que se fraguó con la puesta en marcha, en 1993, del Museo del Chocolate. Dicho museo muestra el proceso de fabricación del chocolate, ofrece la posibilidad de apreciar utensilios en diferentes materiales, fotos de maestros chocolateros, pero también es representativo de la influencia de esta actividad en la vida de la ciudad y de la comarca.

Mapa 4. Estructura sectorial de la industria en las montañas del NW de Castilla y León.

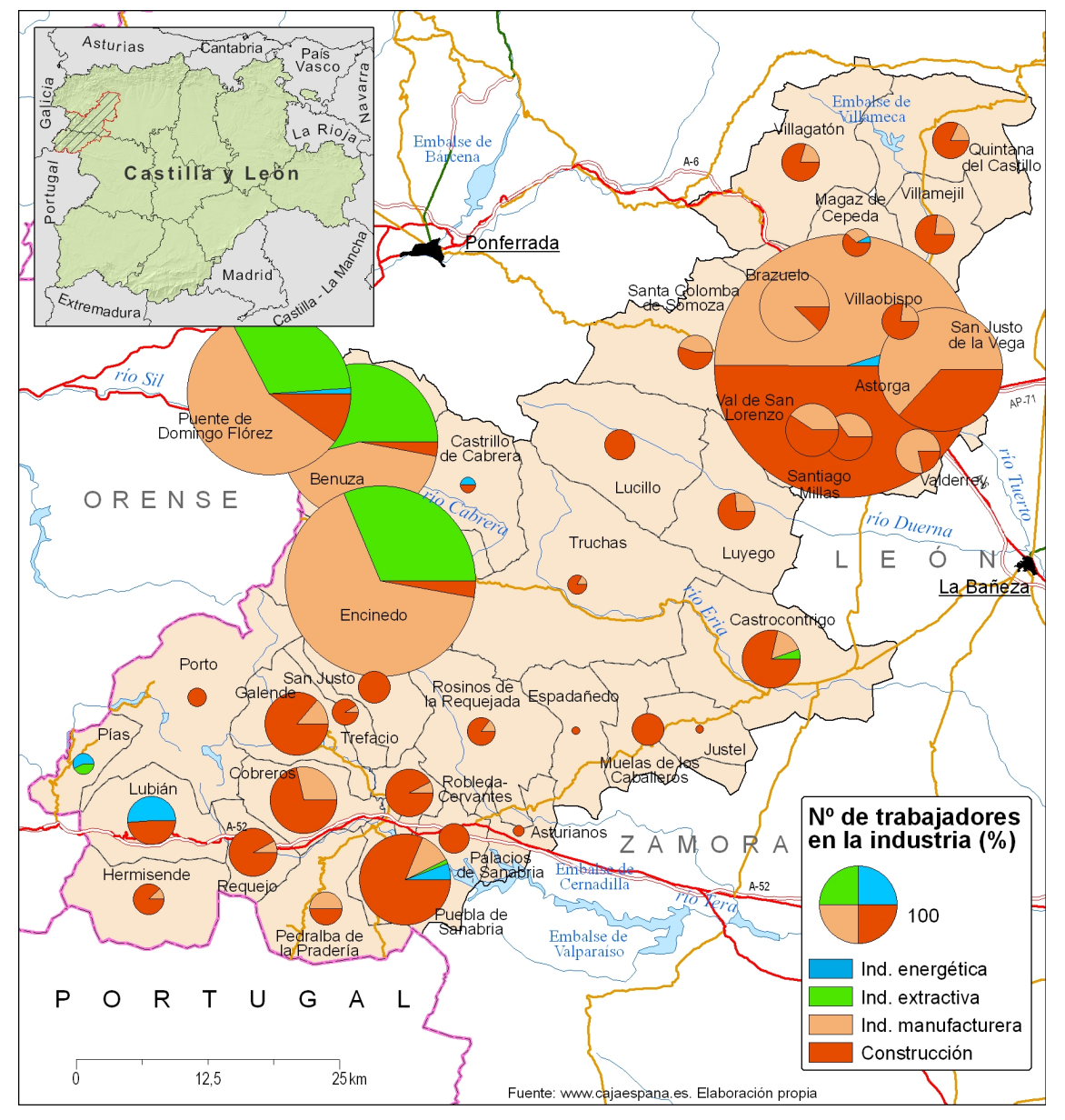


Las mantecadas de Astorga son otro producto representativo de la ciudad desde el siglo XIX. En este caso, parece que una monja del convento de Sancti Spiritus rescató la receta y varios confiteros de la ciudad las elaboraban como dulces de Navidad para el Seminario astorgano. Sin embargo, no será hasta 1850 cuando en Astorga se funden los primeros obradores, iniciándose la andadura comercial del producto, aprovechando la línea férrea (Ferrocarril del Norte y del Oeste). Una actividad que conllevó la aparición de un nuevo oficio, las cajilleras, encargadas de preparar a mano las cajillas de papel en las que se elaboran las mantecadas. Desde el año 2004 las mantecadas de Astorga gozan de Indicación Geográfica Protegida; se trata de una marca que certifica su origen (elaboradas por las industrias inscritas en el Registro de Obradores) y reconoce la calidad del producto, avalada por el Consejo Regulador que es el órgano encargado de controlar y certificar dicha calidad. La Indicación Geográfica Protegida incluye a varios municipios de los Montes de León, en concreto Astorga, Brazuelo, San Justo de la Vega y Valderrey.

Dentro de la industria alimentaria destaca la rama de transformados cárnicos (26,9\% de las manufacturas alimentarias). En la implantación de esta industria influyen factores como la disponibilidad de materias primas agrarias, la facilidad de aprovisionamiento de esta industria transformadora y los ejes viarios o la atracción de grandes centros de consumo como la capital de la provincia y del país. A estos factores se suma la calidad del producto que está avalada por la consecución de marcas de garantía, como es el caso de la Indicación Geográfica Protegida de la Cecina de León, cuyo Consejo regulador se ubica en el edificio de la Cámara de Comercio de Astorga. Por regla general, se trata de pequeñas y medianas empresas que contribuyen a diversificar el tejido productivo local, basado en el aprovechamiento del potencial endógeno, como un método adecuado para mejorar las perspectivas económicas de la zona. En este sentido, conviene mencionar algunos ejemplos de industrias artesanales dedicadas a la elaboración de embutidos, como Cecinas Pablo, Cecinas Garrote, Embutidos Evilio Corleal, en Astorga o Cecinas Nieto en Pradorrey, que ponen de manifiesto la tradición existente en cuanto a la transformación de esos productos locales.

Otra de las huellas que perviven en la comarca es la industria textil de Val de San Lorenzo. Esta actividad, vinculada al tejido de paños de lana, se encuentra presente desde el siglo XVIII en el municipio y en otros pueblos cercanos y ribereños del Turienzo, donde la población simultaneaba la actividad agraria con el tejido de paños y otras labores textiles, como la tradición casera del tejido del lino y lana. Según el Marqués de la Ensenada, 1752 "digeron haber en este lugar; ochenta y un fabricantes de paño que ganan veinte y dos mill quinientos quarenta reales vellón, en cuatro meses de el año que se necesitan para su fa- 
brica y benta, quedandoles a su beneficio ocho meses, que se emplean por la mayor parte en el oficio de cardar y peinar lana, dentro y fuera de este lugar".

Durante el primer tercio del siglo XIX la competencia catalana afectó a la industria pañera del municipio. A partir de 1858 José Cordero Geijo sustituirá la fabricación de paños por la de cobertores con dibujos y colores de identificación Maragata, conocidos como barrendos; además, en 1919 se crea "La Unión del gremio de Fabricantes" y en 1920 se pone en funcionamiento "La Comunal", la primera fábrica con maquinaria moderna destinada al cardado e hilado de la lana.

En la actualidad, la industria textil continúa ostentando la hegemonía del panorama manufacturero de este municipio, a pesar de las crisis que le han afectado a lo largo del siglo XX: reducción del empleo en los años sesenta debido a la tecnificación, crisis generalizada de la economía nacional e internacional de mediados de los setenta y crisis de los noventa y actual. Estas últimas crisis han supuesto la desaparición de algunas empresas y la pérdida de puestos de trabajo. Otros factores que influyen en la regresión del sector textil son: la atonía de la demanda de un producto tradicional de alta calidad que no puede competir en precio con tejidos importados, la escasa renovación productiva y generacional y el hecho de que el producto de la localidad se encuentra a medio camino entre la artesanía y la industria. A estos factores se pueden añadir, como en otras áreas de la Comunidad, "las limitaciones en la gestión y dirección de empresas, así como el retardo (cuando no ausencia) en la puesta en marcha de estrategias activas de adaptación al cambio económico y a las nuevas condiciones de competencia" (ALONSO; APARICIO; SÁNCHEZ: 2000: 134).

A pesar de esta situación, que ha llevado a muchas empresas a reajustar el proceso de trabajo y reducción de personal, esta actividad artesanal, continúa fabricando todo tipo de productos textiles a partir de pura lana virgen. La tejeduría en el Val de San Lorenzo abarca varias fases (cardaje-hilado-tejidoperchado), ofreciendo piezas tradicionales de gran belleza y valor etnográfico, como son las famosas mantas de lana blanca con sus características bandas en verde, azul y malva o rojo y azul. También la artesanía textil de la zona ofrece diseños de chales, ponchos, calcetines, mantas de viaje etc. Precisamente en la fase de tejido de la lana es donde se han realizado los mayores esfuerzos en innovación y comercialización; a pesar de ello la producción pañera ha ido disminuyendo desde los años noventa tanto en volumen de ventas como en producción, ante la dificultad para competir con precios competitivos en el mercado. Otra deficiencia es la inexistencia de una Agrupación de Fabricantes (como existió en el pasado) y las deficiencias en la promoción de una imagen colectiva de las mantas del Val de San Lorenzo, como marca o producto de calidad, siendo ésta una de las principales debilidades del sector. Pese a ello, esta actividad 
sigue siendo el principal generador de riqueza en el panorama industrial local y las huellas de la tradición textil perviven en la calidad del producto, siendo ésta su mayor ventaja competitiva.

La difusión de la cultura textil está presente en el municipio con la implantación de proyectos musealizadores que se han plasmado en el Centro de Interpretación Textil La Comunal y el Batán Museo. Estos dos centros se complementan entre sí, pues abarcan dos fases distintas de la manufactura textil de paños y cobertores de lana. En el Batán está reflejado el tratamiento de los vellones y el batanado o pisado, como prefieren denominarlo los artesanos de la zona, mientras que en el Centro de Interpretación, se explica la historia de los textiles a través de audiovisuales, de colecciones de fotografías e imágenes pintadas en acuarela por la Escuela de Cerámica de Madrid.

Se constata que los rasgos que definen la estructura industrial de la comarca no puede valorarse al margen de la herencia histórica, cuyas huellas son todavía perceptibles no sólo en ejemplos de patrimonio o arqueología industrial (fábricas, molinos, batanes, etc.), sino también en las líneas de especialización dominantes de la actividad industrial. De este modo, y merced a esa herencia histórica, la industria manufacturera, en concreto la rama textil y alimentaria, está influyendo, en grado variable, en el presente socioeconómico de los Montes de León.

\section{VALORACIONES DE LOS CAMBIOS Y DE LAS PERMA- NENCIAS EN LAS MONTAÑAS DEL NOROESTE DE CASTI- LLA Y LEÓN.}

En estos espacios rurales los cambios y las permanencias en las estructuras agrarias son las dos caras de un mismo proceso que les ha afectado directamente y ha causado importantes transformaciones en el conjunto de los municipios de las montañas del Noroeste de la región.

Los cambios están relacionados, sin duda, con las situaciones y con las dinámicas socioeconómicas que han afectado al conjunto de los espacios rurales. En este caso, la emigración, los procesos de mecanización y tecnificación del proceso de producción agrario o la adecuación a las nuevas demandas y exigencias de la sociedad actual han incidido de manera integrada en varios aspectos, entre los cuales se pueden mencionar: la reducción de los activos agrarios, el envejecimiento de la población rural y en particular de los titulares, la desaparición de muchas explotaciones, las modificaciones en los usos y aprovechamientos agrarios, la mecanización de las labores agrícolas o la caída en desuso, e incluso su desaparición, de las prácticas colectivas y de la gestión en común de los bienes comunales, que constituían recursos frágiles y muy valiosos para la superviven- 
cia de la propia sociedad rural. En fin, son transformaciones que se integran en un contexto más amplio, cuyas causas están imbricadas con el conjunto del sistema económico y que, por supuesto, han afectado por doquier a todos los espacios rurales provinciales.

Las pervivencias se asocian a aquellas manifestaciones que, aunque han sido afectadas por los cambios, aún mantienen cierta vigencia. Dentro de las mismas se pueden poner de relieve: el predominio de las explotaciones agrarias de pequeñas dimensiones, que siguen constituyendo una rémora para la economía comarcal, pero se hallan en consonancia con la propia situación agraria de la comarca; el número y el tamaño de las parcelas, que no favorecen los procesos de mecanización o la SAU por explotación que aún siendo pequeña, está ajustada a las propias estructuras agrarias municipales. De cualquier modo, no dejan de ser claras evidencias del peso relativo que aún ostenta el sector agrario en la comarca, cuya población tiene que ser capaz de ir incorporando otras actividades económicas con el fin de diversificar las fuentes de ingresos, como la industria de la pizarra o el turismo rural.

En estos territorios de montaña sus perspectivas de futuro dependen de las estrategias que adopten las empresas para aumentar la competitividad, en especial en un sector como el agroalimentario, muy sensible a los efectos de la competencia, a los desafíos de las coyunturas y a la consolidación de economías de escala. Así pues, parece que el devenir empresarial de estos territorios pasa por su inserción en el mercado, buscando aquellos segmentos más exigentes, donde más que la cantidad prime la calidad del producto; una calidad que, en estos territorios, viene avalada por la tradición. Para ello, habrán de poner todo su empeño en mejorar la calidad del producto y del proceso, en desarrollar un distintivo de marca (diferenciación del producto) y en la salida hacia mercados extrarregionales (estrategia comercial más agresiva, presencia en ferias internacionales...). El objetivo sería aprovechar los recursos endógenos de la zona para impulsar proyectos que dinamicen la vida económica local y que vayan arraigando los principios de la multifuncionalidad en estos espacios rurales para mantener determinados niveles de articulación territorial y socioeconómica.

\section{BIBLIOGRAFÍA}

AlONSO, J.L.; APARICIO, J. y SÁNCHEZ, J.L. (2000): «La reestructuración de la industria textil en Béjar y sus efectos en el mercado local de trabajo», en LOZANO MALDONADO, J.M. (coord.): Nuevas tecnologías, trabajo y localización industrial, Granada, AGE, 125-139.

ALONSO GonZÁLEZ, P. (2008): «Arqueología industrial y patrimonio. Posibilidades de regeneración en el Val de San Lorenzo y Astorga», en Argutorio, n 20, 37-41. 
AlONSO GonZÁLEZ, P. (2009): Etnoarqueología y gestión del patrimonio cultural: Maragatería y Val de San Lorenzo. Universidad de León, Junta de Castilla y León y Ayuntamiento de Val de San Lorenzo.

CABero DiÉGUez, V. y López TRIGAL, L. (Coords.): La provincia de León y sus comarcas, León, Diario de León.

Casado Lobato, C. (1998): Batán-Museo Val de San Lorenzo. León, Instituto Leonés de Cultura.

CATASTRO DEl MARQuÉS de LA ENSENADA, 1752.

GonZÁlez PÉREZ, C. (1999): «El Museo del Chocolate de Astorga», en Cuadernos de etnología y etnografía de Navarra, $\mathrm{n}^{\mathrm{o}} 73,315-322$.

MAYA FRADES, A. (2008): El desarrollo rural como estrategia territorial: las perspectivas de los espacios rurales en Castilla y León, León, Secretariado de Publicaciones de la Universidad de León.

MAYA FRADES, A. (1999): «La propiedad colectiva en el Noroeste de España: el derecho consuetudinario en la provincia de León», en NERVI, P. (Ed.): Dominio collettivi e autonomia, Padova, Università Degli Studi di Trento, 41-69.

Maya Frades, A., PAscual, M. R. y CABero DiÉGuez, V. (1998): «Los sistemas comunales de aprovechamiento de pastos en la provincia de León», en SÁNCHEZ LÓPEZ, F. (Ed.): Modelos de gestión de sistemas de recursos comunales en Castilla y León, Valladolid, Junta de Castilla y León, 167-203.

Maya Frades, A., PAscual, M.R. y Gómez Sal, A. (1991): «Propiedad comunal y ocupación del espacio en el sector occidental de la provincia de León», en VV. AA.: Actas del VI Coloquio de Geografía Rural, Madrid, Universidad Autónoma, 135148.

MAya Frades, A., SÁnchez MuÑoz, M. J. y SAn Román Rodríguez, J. M. (2009): «Recientes dinámicas territoriales de las montañas del Noroeste de Castilla y León: basadas en el turismo rural», en VV. AA.: XXI Congreso de Geógrafos Españoles “Geografía, Territorio y Paisaje: el estado de los cuestión”, Ciudad Real, AGEUniversidad de Castilla-La Mancha.

PlAZA GUTIÉRREZ, J.I. (2000): «Espacios naturales, territorio y desarrollo (reflexiones teóricas y sobre formas de gestión. Algunos ejemplos de la región castellanoleonesa)»; en VAlle Buenestado, B. (Coord.): Geografía y Espacios Protegidos, Murcia, Asociación de Geógrafos Españoles, Federación de Espacios Naturales Protegidos de Andalucía, 311-332.

ROSSELL J. y VILADOMIU L. (1998): «Creación de empleo no agrario en provincias de baja densidad demográfica», en VV.AA.: Actas del VI Congreso de Economía de Castilla y León. Zamora. Junta de Castilla y León.

Rodríguez GonzÁlez, X. A. y SAN RomÁn RodrígueZ, J. M. (1997): A industria da Lousa: unha panorámica, IDEGA, Documento de Traballo, Xeografía 1, Universidade de Santiago de Compostela.

SÁNCHEZ MuÑOZ, M. J. (1998): «Los Programas de Desarrollo Rural en la provincia de León», en Polígonos. Revista de Geografía, nº 8, 151-176.

SÁnchez Muñoz, M. J., SÁnchez Hernández, J. L., Moro Gutiérrez, L. y ZAPATERO ZAPATERO, J. (1996): La inversión industrial en Castilla y León durante el quinquenio expansivo (1985-89). Junta de Castilla y León. Consejería de Economía y Hacienda. Documento inédito. 
SÁNCHEZ MuÑoz, M.J., SÁNCHEZ HERnÁNDEZ, J. L., MORO GuTIÉRREZ, L. y ZAPATERO ZAPATERO, J. (1996): La inversión industrial en Castilla y León durante la crisis de los noventa: Análisis sectorial y territorial. Junta de Castilla y León. Consejería de Economía y Hacienda. Documento inédito

SAN RomÁn RodrígUEZ, J. M. (1998): «La raza bovina Alistana-Sanabresa en el municipio de Porto de Sanabria (Zamora)», en VV.AA.: IX Coloquio de Geografía Rural. Vitoria, Universidad del País Vasco, 493-502.

SAN ROMÁN RODRÍGUEZ, J. M. (2000): «La automatización de las centrales hidroeléctricas en las cuencas del Sil y su afluente el Bibei: Los cambios en el empleo y el abandono de los poblados: Ourense y Lugo» en LOZANO MALDONADO (Coord.): Nuevas tecnologías, trabajo y localización industrial, Granada, AGE, Universidad de Granada, 141-154.

SAN ROMÁN RODRÍGUEZ, J. M. (2000): «Los espacios naturales del Bierzo y La Cabrera (León): Minería y desarrollo rural», en VV.AA.: Los espacios rurales en el cambio de siglo: incertidumbres ante los procesos de globalización y desarrollo, Lleida, AGE, Universidad de Lleida, 468-477.

SAN ROMÁN RoDRÍGUEZ, J. M (2003): «Impacto de las ocupaciones de montes en el Macizo de Trevinca: cambios en el paisaje y transformaciones socioeconómicas. Municipio de Puente de Domingo Flórez (León)»; en Actas de la II Reunión sobre Historia Forestal; Cuad. Soc. Esp. Cie. For., nº 16, 207-213.

SAN ROMÁN RODRÍGUEZ, J. M (2008): «Crisis y potencialidades de la cabaña ganadera en el Macizo de Trevinca. (Galicia y Castilla y León)», en VV.AA.: Actas XIV Coloquio de Geografía Rural, Murcia, Universidad de Murcia, 83-93. 